\title{
Improved Ten-Picofarad Fused Silica Dielectric Capacitor ${ }^{1}$
}

\author{
R. D. Cutkosky and L. H. Lee
}

(March 8, 1965)

\begin{abstract}
Some defects in a set of fused silica dielectric capacitors constructed in 1961 are listed, and methods for their reduction or elimination are described. The construction of a new set of capacitors completed in 1964 is described in detail. Preliminary stability data presented indicate that the typical drift of the 1964 capacitors with respect to their mean was less than two parts in $10^{7}$ in five months.
\end{abstract}

\section{Introduction}

Capacitors utilizing fused silica as the dielectric have been under investigation at NBS and elsewhere $[1]^{2}$ for many years. Early indications were that suitably constructed capacitors of this type would be at least as stable as air capacitors, and additionally would be sufficiently rugged to withstand shipment between laboratories.

A set of four fused silica dielectric 10-pF capacitors was constructed at NBS in 1961 [2]. The capacitance elements of these capacitors consisted of fused silica disks $7 \mathrm{~cm}$ in diameter and $1 \mathrm{~cm}$ thick. Silver electrodes were fired on the two faces of the disks and a third electrode was fired on the cylindrical surface. The cell in which the element was mounted shielded the face electrodes from each other in the region external to the fused silica element, and was connected electrically to the cylindrical electrode of the element. The housing contained a four-terminal resistance thermometer for temperature measurement and was hermetically sealed.

One of the 1961 capacitors was successfully handcarried to several distant laboratories and returned. These laboratories included NRC (Canada), NPL (England), and NBS Boulder. The largest change in capacitance observed upon completion of the round trip was 0.2 parts in $10^{6}(\mathrm{ppm})$. A shipment of this capacitor by commercial carrier was not successful and resulted in a change in its capacitance of 36 ppm. This change was traced to a sensitivity to severe mechanical shock.

The 1961 capacitors had a number of undesirable features, the shock sensitivity being by far the most important. Further investigation indicated that all of the capacitors in the set suffered from this flaw, and that the change in capacitance was caused by motion of the fused silica element in its cell. The element was supported in the cell by means of phosphor bronze springs which permitted motion of the element along the cell axis. The element could not return to its equilibrium position after displace-

1 This work was supported in part by the Metrology Engineering Center, Bureau of Naval Weapons, Pomona, Calif.

${ }_{2}^{2}$ Figures in brackets indicate the literature references at the end of this paper. ment because of frictional forces between the cylindrical surface of the element and the spring contacts attached to the cell. This mechanism could not have caused a capacitance change if the direct electrical field between the face electrodes had been entirely within the fused silica. Unfortunately, the direct capacitance included a small contribution due to fields from the back of a face electrode which entered the fused silica element at the insulation gap between this face electrode and the cylindrical shield electrode, and terminated at the opposite face electrode. Motion of the element within its cell altered the leakage field and consequently changed the total direct capacitance.

A second flaw in the 1961 capacitors was a pronounced dependence of capacitance upon voltage. It was necessary to restrict the voltage applied to these capacitors to $10 \mathrm{~V}$ rms to reduce the measurement uncertainty from this cause below $0.1 \mathrm{ppm}$. Since sufficient sensitivity is a vailable at this voltage to see one part in $10^{7}$, the voltage dependence did not seriously limit measurement accuracy. An investigation into the mechanism of the voltage dependence was made, and it was found that the dependence could be almost eliminated by increasing the thickness of the fired silver electrodes. The evidence indicates that the existence of islands of silver on the dielectric surface which are not in good electrical contact with the body of the electrode is in some way responsible for the large voltage dependence. A similar effect has been observed in mica capacitors with fired or deposited silver electrodes [3].

Measurements of capacitance and dissipation factor as a function of frequency indicated a capacitance difference from $50 \mathrm{~Hz}$ to $20 \mathrm{kHz}$ of about $25 \mathrm{ppm}$, with a maximum slope and a maximum dissipation factor at about $1600 \mathrm{~Hz}$. The shape of the curve suggested a relaxation mechanism involving polar impurities in the fused silica. An investigation of several optical grades of fused silica disclosed that the use of a grade possessing exceptionally good ultraviolet transmission characteristics resulted in capacitors with very much smaller frequency dependencies and with dissipation factors not greater than $3 \times 10^{-6}$ throughout the audio-frequency region.

Examination of the published optical characteristics for the various grades tested disclosed no correla- 
tion between optical absorption and audio-frequency behavior. It is felt that the presence or absence of the audio-frequency relaxation phenomenon is an accidental result of the technique for producing fused silica. It is possible that changes in manufacturing technique which have no effect on the optical properties of the fused silica may greatly affect the audio-frequency characteristics.

The temperature coefficients of the 1961 capacitors were about $14 \mathrm{ppm} /{ }^{\circ} \mathrm{C}$. The large values were believed to be the result of a large temperature coefficient of dielectric constant in fused silica. Resistance thermometers were built into the capacitor housings to eliminate the measurement uncertainties caused by unknown temperatures.

A set of twelve 10-pF fused silica dielectric capacitors was built in 1964. Care was taken to reduce greatly all of the flaws listed above. The capacitance elements were constructed of type II Suprasil, ${ }^{3}$ and were supported in their cells by means of tightly fitting polytetrafluoroethylene (P'TFE) rings. Care was taken to keep the gaps between the face electrodes and the cylindrical shield electrode as small as seemed consistent with operation up to $200 \mathrm{~V}$ rms. The voltage dependence of each capacitor was measured before final sealing, and the electrodes were replated when necessary. The 1964 capacitors are physically smaller and much lighter than the 1961 capacitors, but were not designed with this as a principal objective.

The construction of these new capacitors is described in some detail to allow their reproduction elsewhere. Some characteristics of the completed set are then presented.

\section{Construction}

\subsection{Housing}

A cross section of the capacitance standard is shown in figure 1. The exterior of the assembly is constructed entirely of stainless steel. The hermetically sealed region at the bottom containing the fused silica element is welded shut upon completion, and after baking, the container is filled with dry $\mathrm{N}_{2}$ through a copper sealoff tube. Electrical connections are made to the capacitor element and to the four-terminal resistance thermometer by means of glass-Kovar seals soft soldered to the sealed compartment.

Electrostatic shields not shown in figure 1 isolate the two face electrode leads from each other and from the resistance thermometer leads. The face electrode leads pass through stainless steel tubes as shown to a pair of coaxial connectors located above the liquid level of a constant-temperature oil bath. The resistance thermometer leads are attached to four binding posts located below the liquid level. Details of the construction can be seen in figure 2 .

\footnotetext{
${ }^{3}$ Available from Amersil Quartz Cumpany.
}

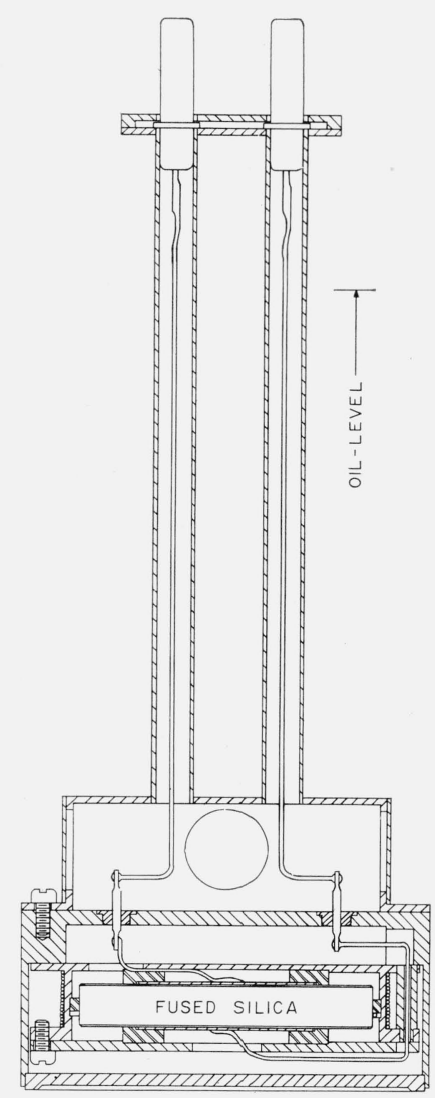

Figure 1. Cross section of the capacitance standard.

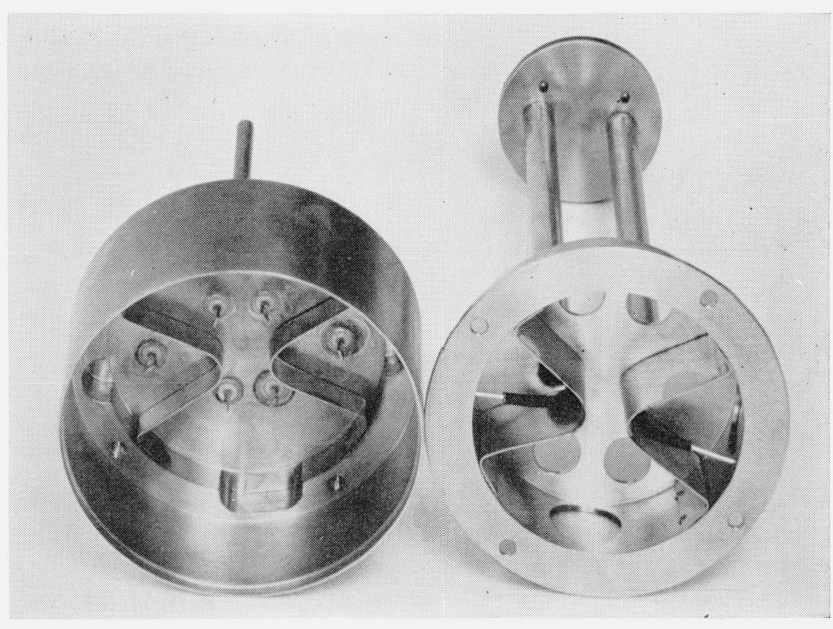

FIGURE 2. Details of the capacitor housing and superstructure.

The dimensions of the fused silica element and its mounting are shown in figure 3 . The P'TFE radial support is inserted into the slot of the brass cell before the inside diameter of the PTFE is finish machined. Each fused silica element is individually fitted to its cell by machining this radial support so 


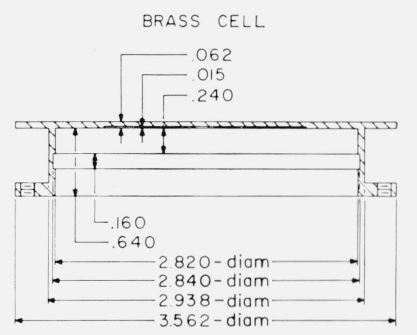

PTFE RADIAL SUPPORT

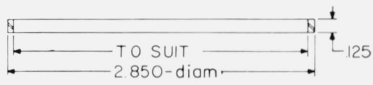

PTFE AXIAL SUPPORT
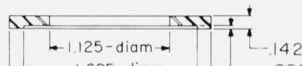

-1625-diam -

OIO-INCH PHOS BRONZE SPRING, I620-D

USED SILICA ELEMENT
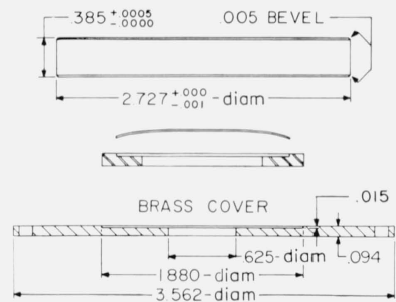

Figure 3. Fused silica capacitancelement and cell dimensions

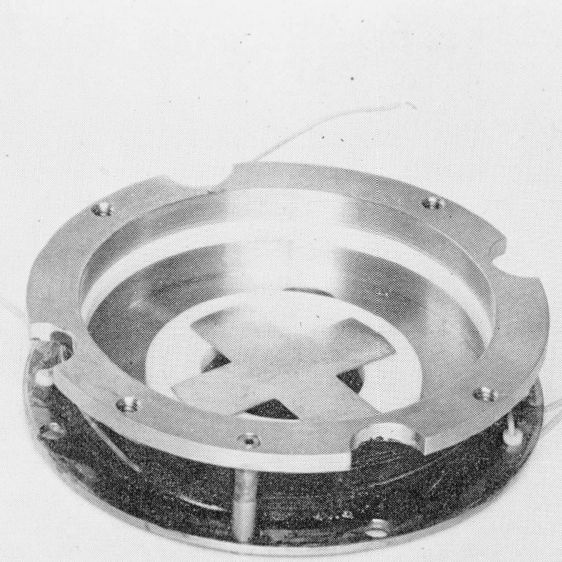

Figure 4. Partially assembled capacitance element cell. that the element with its silver electrodes in place can just be removed from the cell with a rubber suction cup. The axial (vertical) constraint on the element is controlled by the use of shims or by machining, so that an axial interference of about $0.001 \mathrm{in}$. is obtained. This results in a slight compression of the P'TFE axial supports.

Electrical connections to the face electrodes on the fused silica element are made by means of wires soldered to the phosphor bronze disk springs shown in figure 3. The disks are cut to the shape of an $X$ and bent as shown in figure 4. Electrical connection between the cylindrical electrode and the cell is made by inserting three 0.030 -in. diam phosphor bronze wires about 2 in. long into the circular gap between the cell and the element. The ends of these wires lie in the slot at the sides of the cell with the PTFE radial support. The three wires are positioned uniformly around the circumference of the cell and provide three points of electrical contact.

\subsection{Resistance Thermometer}

The four-terminal thermometer is located on the outside of the cell containing the fused silica element, as shown in figures 1 and 4 . The cell is prepared by cementing a layer of linen cloth over it with shellac and baking at $100{ }^{\circ} \mathrm{C}$. A length of $\mathrm{B} \& \mathrm{~S}$ No. 36 Formvar insulated copper wire with a resistance of $25 \Omega$ is doubled over and wound bifilarly over the linen. More shellac is then applied and baked. Leads to the current and potential terminals are connected to the resistance wire with soft solder. The junctions are tied down securely and shellac is applied. The completed thermometer is baked for $24 \mathrm{hr}$ at $75^{\circ} \mathrm{C}$.

\subsection{Fused Silica Element}

The fused silica element is ground to the dimensions shown in figure 3 with conventional toolroom grinding equipment. Some care is necessary to prevent chipping of the edges. After inspection for chips, the element is cleaned with alcohol, and then with soap and water. It is next immersed in an ultrasonic cleaning bath containing a wetting agent, and rinsed with water. Finally, it is immersed in an ultrasonic cleaning water bath and rinsed with distilled water. After drying at $100{ }^{\circ} \mathrm{C}$, Dupont Silver Paint \#4666 is sprayed onto one face and the cylindrical surface, and allowed to air dry. The other face is then sprayed and dried, and the silver is fired onto the element at $480{ }^{\circ} \mathrm{C}$. It is found that single silver deposits thicker than 0.0005 in. are often defective, and that a single application is not sufficient to prevent a dependence of capacitance upon voltage. A satisfactory remedy is to buff the electrode surface with fine steel wool and apply two additional coats of paint to the electrodes. The preferred final electrode thickness is between 0.0010 and $0.0015 \mathrm{in}$. If the electrode thickness is increased to 0.002 in., the large thermal expansion coefficient of the silver often causes the fused silica element to chip when it is 
cooled from the firing temperature. No noticeable chipping occurs when the silver thickness is less than 0.0015 in.

After the third electrode coat has been fired, the edges of the element are very lightly beveled to separate the cylindrical electrode from the face electrodes. This is done by hand with a diamond wheel and a special jig, using water as a lubricant. Care must be taken at this point to avoid making the gap excessively wide and to remove all traces of silver from the beveled portions of the fused silica. If the diamond wheel is allowed to become contaminated with silver, a thin layer of silver will remain on the fused silica, and a large dependence of capacitance upon voltage will result.

The element is next fitted to its cell by machining the PTFE radial support. The element is then baked $24 \mathrm{hr}$ in vacuum at $175{ }^{\circ} \mathrm{C}$ to eliminate adsorbed water, placed in its cell, and the cell is evacuated. The baking and evacuation are essential to produce a small dissipation factor and a stable capacitance.

After the capacitor has reached room temperature, it is measured and the adjustment necessary to produce exactly $10 \mathrm{pF}$ at $25^{\circ} \mathrm{C}$ is estimated. Using the element and cell dimensions shown in figure 3 , the capacitance will probably not depart from $10 \mathrm{pF}$ by more than \pm 0.05 percent. An adjustment as small as this can be made quite easily by cutting a cavity into either a face or the cylindrical surface of the element with a small diamond wheel. The cavity is then sprayed with silver paint and refired. The adjustment sensitivity depends upon the diamond wheel diameter and thickness, the depth of cut, and the position of the cavity on the element. A jig may be readily set up to regulate depth of cut, and a calibration of capacitance change versus depth of cut measured with a trial element. Usually two or three successive adjustments suffice to produce a capacitance of $10 \mathrm{pF} \pm 50 \mathrm{ppm}$. A typical fused silica element after adjustment is shown in figure 5 .

After final adjustment, a test is made for voltage dependence, and if necessary, the entire element is replated. The stainless steel housing is then welded shut, and the system is baked at $65^{\circ} \mathrm{C}$ with a vacuum pump attached to the sealoff tube. After cooling,

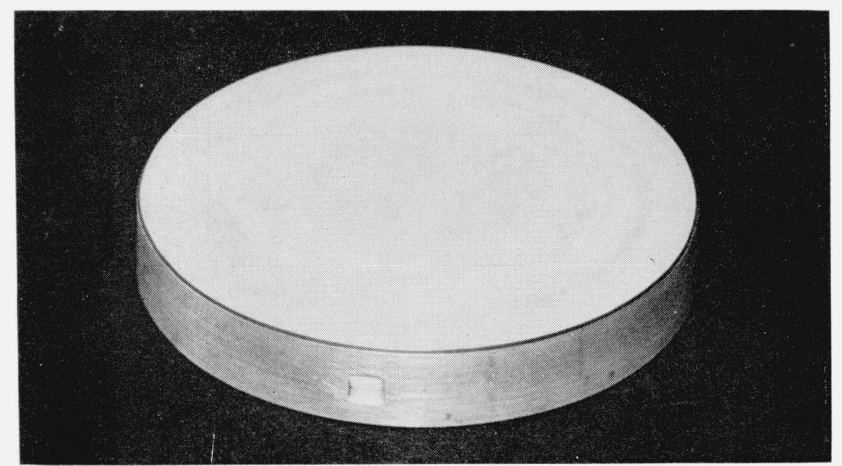

FIGURE 5. Completed fused silica element with an adjustment of minus $50 \mathrm{ppm}$. the housing is filled with dry $\mathrm{N}_{2}$ at atmospheric pressure, and the sealoff tube is pinched off and soldered. A series of temperature cyclings is made between 50 and $0^{\circ} \mathrm{C}$, and the unit is placed into operation. Figure 6 shows a completed capacitor.

\section{Performance}

\subsection{Capacitance Stability}

All measurements of capacitance stability reported here were made at $1592 \mathrm{~Hz}$ using a 10:1 bridge, with all capacitors in an oil bath maintained at $25.0^{\circ} \mathrm{C}$. The measurements seemed to indicate that these capacitors were at least as stable as any other capacitors in our laboratory. Accordingly, the mean of five of these capacitors, numbers 108, 109, 110, 112, and 113 was taken to be the basis for the comparisons. No temperature corrections were applied since the capacitors were at nearly the same temperature and had nearly identical temperature coefficients. The application of individual corrections for temperature slightly reduces the scatter in the measurement series reported below. Initially, all measurements were made with $10 \mathrm{~V}$ rms applied to the capacitors to allow ready comparison with the 1961 set of capacitors which had large voltage dependencies. Bridge readings were recorded under these conditions to the

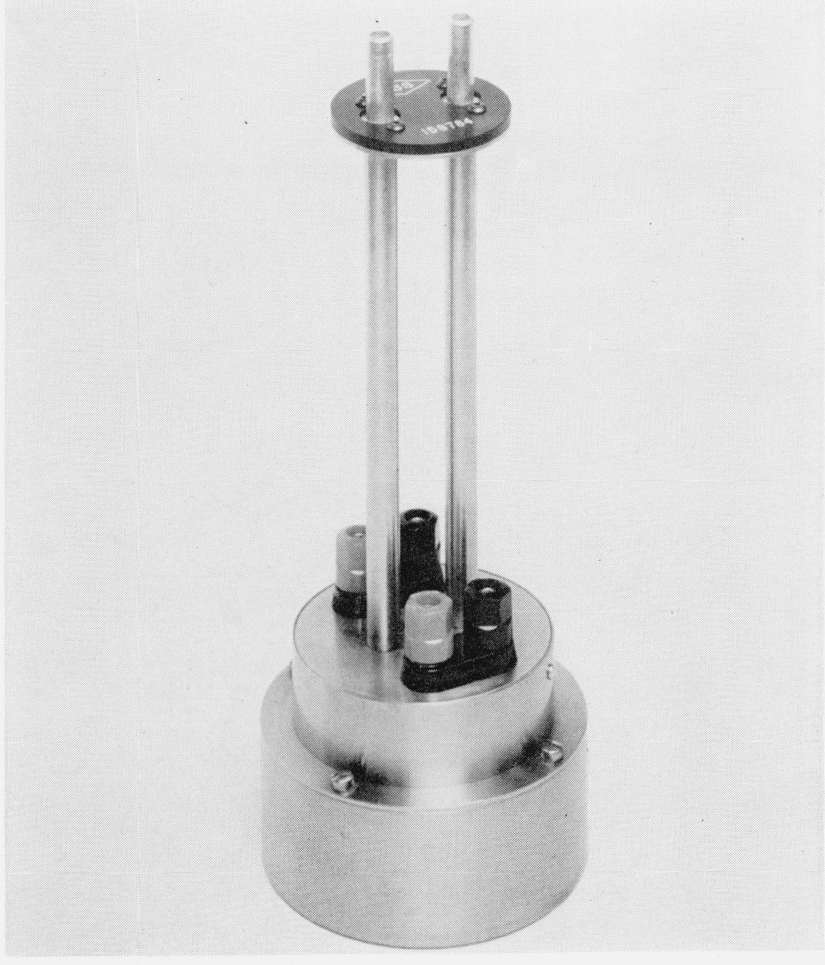

Figure 6. Completed capacitance standard. 
nearest part in $10^{7}$. Beginning November 9, 1964 , the new capacitors were intercompared at $100 \mathrm{~V}$ rms. This allowed considerably greater precision, but prevented simple comparison with the 1961 fused silica capacitors.

Capacitance differences between each capacitor in the set and the mean of the select five are listed in table 1. The table demonstrates that most of the capacitors are stable with respect to each other, but they could possibly all be drifting at the same rate. Comparisons of the 1964 set of capacitors with the 1961 set indicate no appreciable relative drifts, but conclusive proof of stability must await the completion of a new calculable capacitor.

TABLE 1. Relative stability of eleven fused silica capacitors

Decimal points indicate parts in $10^{6}$.

\begin{tabular}{|c|c|c|c|c|c|c|c|c|c|c|c|}
\hline \multirow{2}{*}{ Date } & \multicolumn{11}{|c|}{ Capacitor } \\
\hline & 108 & 109 & 110 & 111 & 112 & 113 & 114 & 115 & 116 & 117 & 118 \\
\hline $\begin{array}{l}8 / 4 / 64 \\
8 / 4 \\
8 / 17 \\
8 / 26 \\
9 / 8 \\
9 / 11 \\
9 / 22 \\
10 / 5 \\
10 / 20 \\
10 / 22 \\
10 / 30 \\
11 / 5 \\
11 / 9 \\
11 / 16 \\
11 / 24 \\
11 / 30 \\
12 / 7 \\
12 / 14 \\
12 / 21 \\
12 / 28 \\
1 / 4 / 65 \\
1 / 12 \\
1 / 19 \\
1 / 26\end{array}$ & $\begin{array}{l}-2.5 \\
-2.5 \\
-2.5 \\
-2.5 \\
-2.6 \\
-2.6 \\
-2.6 \\
-2.6 \\
-2.5 \\
-2.5 \\
-2.5 \\
-2.5 \\
-2.57 \\
-2.53 \\
-2.53 \\
-2.58 \\
-2.59 \\
-2.62 \\
-2.52 \\
-2.56 \\
-2.51 \\
-2.50 \\
-2.50 \\
-2.50\end{array}$ & $\begin{array}{l}+1.6 \\
+1.6 \\
+1.5 \\
+1.5 \\
+1.6 \\
+1.5 \\
+1.5 \\
+1.5 \\
+1.6 \\
+1.6 \\
+1.6 \\
+1.5 \\
+1.58 \\
+1.57 \\
+1.54 \\
+1.55 \\
+1.56 \\
+1.56 \\
+1.55 \\
+1.55 \\
+1.54 \\
+1.54 \\
+1.54 \\
+1.54\end{array}$ & $\begin{array}{l}-28.3 \\
-28.3 \\
-28.3 \\
-28.3 \\
-28.2 \\
-28.2 \\
-28.2 \\
-28.2 \\
-28.2 \\
-28.2 \\
-28.1 \\
-28.2 \\
-28.18 \\
-28.18 \\
-28.15 \\
-28.13 \\
-28.13 \\
-28.12 \\
-28.15 \\
-28.14 \\
-28.15 \\
-28.15 \\
-28.15 \\
-28.15\end{array}$ & $\begin{array}{r}+5.0 \\
+5.0 \\
+5.0 \\
+4.9 \\
+5.0\end{array}$ & $\begin{array}{l}+18.2 \\
+18.2 \\
+18.3 \\
+18.2 \\
+18.2 \\
+18.2 \\
+18.2 \\
+18.2 \\
+18.2 \\
+18.2 \\
+18.2 \\
+18.2 \\
+18.19 \\
+18.18 \\
+18.10 \\
+18.11 \\
+18.12 \\
+18.12 \\
+18.08 \\
+18.09 \\
+18.08 \\
+18.07 \\
+18.06 \\
+18.07\end{array}$ & $\begin{array}{l}+10.8 \\
+10.9 \\
+10.9 \\
+10.9 \\
+10.9 \\
+10.9 \\
+10.9 \\
+10.9 \\
+11.0 \\
+11.0 \\
+11.0 \\
+10.9 \\
+10.98 \\
+10.97 \\
+11.04 \\
+11.06 \\
+11.05 \\
+11.07 \\
+11.04 \\
+11.06 \\
+11.04 \\
+11.04 \\
+11.04 \\
+11.04\end{array}$ & $\begin{array}{l}+31.5 \\
+31.5 \\
+31.5 \\
+31.6 \\
+31.5 \\
+31.5 \\
+31.6 \\
+31.5 \\
+31.5 \\
+31.5 \\
+31.49 \\
+31.46 \\
+31.38 \\
+31.40 \\
+31.41 \\
+31.41 \\
+31.37 \\
+31.37 \\
+31.36 \\
+31.36 \\
+31.36 \\
+31.37\end{array}$ & $\begin{array}{l}+21.6 \\
+21.4 \\
+21.4 \\
+21.5 \\
+21.6 \\
+21.6 \\
+21.6 \\
+21.5 \\
+21.59 \\
+21.59 \\
+21.60 \\
+21.62 \\
+21.60 \\
+21.59 \\
+21.60 \\
+21.56 \\
+21.54 \\
+21.56 \\
+21.56 \\
+21.56\end{array}$ & $\begin{array}{l}+15.6 \\
+15.5 \\
+15.6 \\
+15.6 \\
+15.8 \\
+15.8 \\
+15.8 \\
+15.7 \\
+15.76 \\
+15.73 \\
+15.67 \\
+15.69 \\
+15.68 \\
+15.68 \\
+15.66 \\
+15.64 \\
+15.64 \\
+15.65 \\
+15.65 \\
+15.65\end{array}$ & $\begin{array}{l}-23.2 \\
-23.1 \\
-23.1 \\
-23.0 \\
-22.9 \\
-22.9 \\
-22.9 \\
-22.9 \\
-22.85 \\
-22.87 \\
-22.76 \\
-22.73 \\
-22.74 \\
-22.69 \\
-22.70 \\
-22.69 \\
-22.68 \\
-22.68 \\
-22.67\end{array}$ & $\begin{array}{l}+6.1 \\
+6.1 \\
+6.1 \\
+6.1 \\
+6.23 \\
+6.20 \\
+6.22 \\
+6.26 \\
+6.24 \\
+6.27 \\
+6.21 \\
+6.21 \\
+6.20 \\
+6.21 \\
+6.19 \\
+6.21\end{array}$ \\
\hline
\end{tabular}

Capacitor number 117 exhibits a fairly steady increase of capacitance with time. The electrodes of this capacitor were about 0.002 in. thick. This capacitor also has a large voltage dependence of capacitance, as will be seen later. It is believed that the diamond wheel used to bevel the edges of the element was contaminated with silver.

\subsection{Resistance Stability}

Measurements of each resistance thermometer are plotted in figure 7 . The effect of variations in the mean oil bath temperature was eliminated from the data by plotting the differences between each resistance and the mean of the resistances of capacitors $108,109,110,112$, and 113 .

Figure 7 indicates that the resistance thermometers are quite stable relative to each other, but shows a flaw in our oil bath. Between September 20 and October 10, a blast of air from a fan was directed at the southwest corner of the oil bath, where capacitor number 115 was located. This blast of air introduced a temperature gradient of about $0.02{ }^{\circ} \mathrm{C}$ into the bath and is believed responsible for the relative variations observed on September 22 and October 5.

The stabilities of the copper resistance thermometers were determined from a series of measurements made with a Mueller bridge. A calibrated platinum resistance thermometer in conjunction with measured data for the dependence of the copper resistances upon temperature was used to refer all measurements

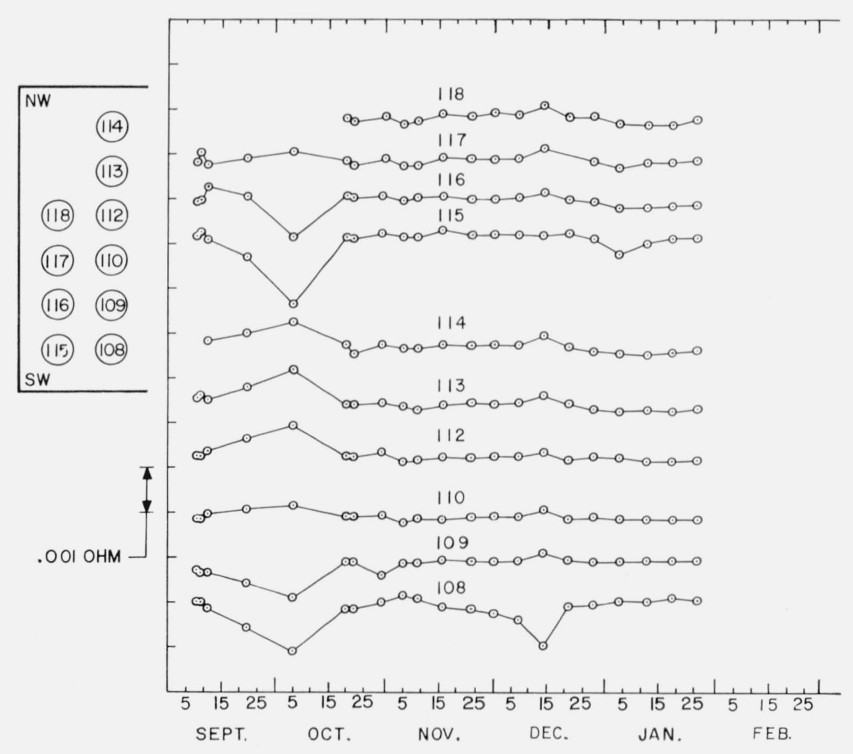

FiguRe $\%$. Relative resistance ther mo meter stability.

Insert shows relative positions in the oil bath. The southwest"corner"was abnormally coldibetween September 20 and October $10 . \quad$ A resistance change of $0.001 \Omega$ corresponds to a temperature change of about $0.01{ }^{\circ} \mathrm{C}$, or a capacitance change of about $0.1 \mathrm{ppm}$. 
to a standard temperature. The limited information currently available indicates that the mean of the five selected resistances at a constant temperature has not changed more than $0.0001 \Omega$ in 2 months. This corresponds to about $0.001{ }^{\circ} \mathrm{C}$; or, referred to a capacitance correction, about $0.01 \mathrm{ppm}$.

\subsection{Temperature Coefficients}

The temperatures of the capacitance standards may be measured by means of the internal $25-\Omega$ resistance thermometers. The capacitances at a specific temperature may then be determined if the capacitance temperature coefficients are known.

In practice, the temperature is usually treated as an implicit variable. A report of capacitance calibration then contains values for the capacitance and for the thermometer resistance at a temperature near $25^{\circ} \mathrm{C}$. A later measurement yielding a different thermometer resistance is corrected to the standard resistance thermometer value by reference to a plot of capacitance versus resistance for the standard.

Measurements of the capacitance-resistance function have been made over the temperature range $20{ }^{\circ} \mathrm{C}$ to $30{ }^{\circ} \mathrm{C}$. The curves deviate from a straight line by about $2 \mathrm{ppm}$ at the extremes and are all concave upwards. The slopes at $25^{\circ} \mathrm{C}$ range from 100.4 $\mathrm{ppm} / \Omega$ to $110.0 \mathrm{ppm} / \Omega$. The actual capacitance temperature coefficients are about $10 \mathrm{ppm} /{ }^{\circ} \mathrm{C}$ which is substantially smaller than the $14 \mathrm{ppm} /{ }^{\circ} \mathrm{C}$ temperature coefficients of the 1961 fused silica capacitors. No explanation for this difference has been found.

\subsection{Hysteresis}

The capacitances of most air or solid dielectric standards at a given temperature depend upon the previous temperatures to which the standards have been subjected. Table 2 shows the magnitude of this hysteresis effect in the 1964 set of capacitors. Prior to September 8 all of the capacitors were subjected to a temperature of $50{ }^{\circ} \mathrm{C}$, and then replaced in the oil bath at $25^{\circ} \mathrm{C}$. On September 8 , their capacitances were measured with respect to a capacitor maintained at $25^{\circ} \mathrm{C}$ throughout the experiment. Following these measurements, the capacitors were cooled to $0{ }^{\circ} \mathrm{C}$, and then placed back into the oil bath. They were measured a second time on September 9 . Table 2 shows that the capacitances increased an average of $0.28 \mathrm{ppm}$ following the $0{ }^{\circ} \mathrm{C}$ treatment. A second subjection to $50{ }^{\circ} \mathrm{C}$ and a return to $25^{\circ} \mathrm{C}$ resulted in the September 11 data in table 2. The capacitances returned most of the way to their original September 8 values, but an average capacitance increase of $0.06 \mathrm{ppm}$ remained. Since the data were only recorded to the nearest part in $10^{7}$, this overall change may not be real. The effect illustrated by table 2 represents one of the most serious faults in the capacitors, and one for which the mechanism is not completely understood. It is believed that the large differential expansion coefficient between the fused silica element and the silver electrodes may be partially responsible.
TABLE 2. Dependence of capacitance upon prior thermal history

September 8 and September 11 data were taken at $25^{\circ} \mathrm{C}$ after subjection to $50^{\circ} \mathrm{C}$; September 9 data were taken at $25^{\circ} \mathrm{C}$ after subjection to $0{ }^{\circ} \mathrm{C}$ (see text). Capacitance differences from the September 8 data are given in parts per million.

\begin{tabular}{c|c|c|c}
\hline \hline \multirow{2}{*}{ Capacitor } & September 8 & September 9 & September 11 \\
108 & 0 & +0.15 & +0.1 \\
109 & 0 & +.35 & .0 \\
110 & 0 & +.45 & +.1 \\
112 & 0 & +.35 & +.1 \\
113 & 0 & +.25 & +.1 \\
115 & 0 & +.25 & +.1 \\
116 & 0 & +.35 & .0 \\
117 & 0 & +.35 & +.1 \\
\hline Mean change & 0 & +.05 & +.06 \\
\hline
\end{tabular}

\subsection{Voltage Dependence}

Some techniques and apparatus were developed recently at NBS for measuring the dependence of 100 and $1000 \mathrm{pF}$ capacitors upon voltage, with uncertainties in the order of 1 part in $10^{9}$ [4]. The equipment was used for measuring the voltage dependencies of the $10 \mathrm{pF}$ capacitors with slightly larger uncertainties. Table 3 shows the capacitance differences observed when the voltage was changed from $100 \mathrm{~V}$ to $200 \mathrm{~V}$. The computed probable error of the data in table 3 is 6 parts in $10^{10}$, and the systematic error is estimated to be less than 2 parts in $10^{9}$. Since the voltage dependence of a standard depends upon which electrode is at ground potential, all of the standards are marked with a "D" near the coaxial connector chosen for the ground potential lead.

TABLE 3. Dependence of capacitance and dissipation factor upon voltage

The increases in capacitance and dissipation factor due to increasing the voltage from $100 \mathrm{~V}$ to $200 \mathrm{~V} \mathrm{rms}$ at $1592 \mathrm{~Hz}$ aie shown.

\begin{tabular}{|c|c|c|}
\hline Capacitor & $\frac{\Delta C}{C}$ & $\frac{\Delta G}{\omega C}$ \\
\hline $\begin{array}{l}108 \\
109 \\
110 \\
112 \\
113 \\
114 \\
115 \\
116 \\
117 \\
118\end{array}$ & $\begin{array}{l}+1.3 \times 10^{-9} \\
-3.6 \\
-5.2 \\
-5.0 \\
-2.6 \\
-1.0 \\
+4.8 \\
-1.8 \\
+12.4 \\
+9.8\end{array}$ & $\begin{array}{l}-3.4 \times 10^{-9} \\
-2.2 \\
+1.2 \\
-4.6 \\
+0.6 \\
+1.0 \\
-0.1 \\
-.3 \\
-2.2 \\
-1.4\end{array}$ \\
\hline
\end{tabular}

\subsection{Frequency Dependence and Dissipation Factor}

The result of comparing the fused silica capacitors with two $10 \mathrm{pF}$ air capacitors at three frequencies is reported in table 4. Capacitor A was constructed with concentric cylindrical electrodes, and capacitor $\mathrm{B}$ with rigid parallel plates. Identical results were obtained at $159 \mathrm{~Hz}$, using the two capacitors, but a significant difference was observed at $15900 \mathrm{~Hz}$. The cause of the discrepancy is not known, but probably involves either mechanical resonances or excessive series inductances in one or both of the 
air capacitors. The measurements at $159 \mathrm{~Hz}$ were extremely difficult to make due to poor bridge sensitivity. The computed probable error of the $159 \mathrm{~Hz}$ data in table 4 is $2 \times 10^{-7}$.

TABLE 4. Frequency dependence of the fused silica capacitors relative to two air capacitors (see text)

\begin{tabular}{|c|c|c|c|c|}
\hline Capacitor & $159 \mathrm{~Hz}$ & $1592 \mathrm{~Hz}$ & $15900 \mathrm{~Hz} \mathrm{~A}$ & $15900 \mathrm{~Hz}$ B \\
\hline & $p p m$ & & $p p m$ & ppm \\
\hline 109 & $\begin{array}{l}+1.3 \\
\end{array}$ & $\begin{array}{l}0 \\
0\end{array}$ & -0.6 & $\begin{array}{l}-1.9 \\
-1.5\end{array}$ \\
\hline $\begin{array}{l}109 \\
110\end{array}$ & $\begin{array}{l}+1.0 \\
+1.8\end{array}$ & $\begin{array}{l}0 \\
0\end{array}$ & $=.2$ & $\begin{array}{l}-1.5 \\
-2.1\end{array}$ \\
\hline 112 & $\begin{array}{r}1.0 \\
+0.2\end{array}$ & 0 & $\begin{array}{r}.0 \\
+.2\end{array}$ & -1.1 \\
\hline 113 & $\begin{array}{r}-1.9 \\
\end{array}$ & 0 & $\begin{array}{r}\text { T. } \\
-\end{array}$ & -2.2 \\
\hline $\begin{array}{l}110 \\
114\end{array}$ & $\begin{array}{r}1.9 \\
+0.1\end{array}$ & 0 & $\begin{array}{r}-9 \\
+.2\end{array}$ & -2.1 \\
\hline $\begin{array}{l}114 \\
115\end{array}$ & $\begin{array}{l}+0.1 \\
+1.2\end{array}$ & 0 & $\begin{array}{l}+.2 \\
-.8\end{array}$ & $\begin{array}{l}-2.1 \\
-3.1\end{array}$ \\
\hline $\begin{array}{l}115 \\
116\end{array}$ & $\begin{array}{l}+1.2 \\
+0.3\end{array}$ & 0 & $\begin{array}{l}-.8 \\
-.3\end{array}$ & $\begin{array}{l}-5.1 \\
-2.6\end{array}$ \\
\hline 117 & $\begin{array}{r}-1.6 \\
+\end{array}$ & 0 & -1.2 & -3.5 \\
\hline 118 & $\begin{array}{r}+1.8 \\
\end{array}$ & 0 & -0.6 & -1.9 \\
\hline
\end{tabular}

Accurate measurements of dissipation factor cannot be made at NBS at this time. Comparisons of the fused silica dielectric capacitors with several types of air capacitors suggest that the dissipation factors of the fused silica capacitors are probably between 0 and $+3 \times 10^{-6}$ at $1592 \mathrm{~Hz}$.

\subsection{Shock Sensitivity}

The capacitors were tested upon completion for shock sensitivity by dropping them onto a hardwood table. Various angles of impact and various heights up to 8 in. were tried. The largest capacitance change observed was 1 part in $10^{7}$ which occurred when a capacitor fell about $8 \mathrm{in}$. in an upright position. Falls through smaller distances usually produced no observable change in capacitance.

\subsection{Transportation Experiences}

A fused silica dielectric capacitor designated number 107 and which was identical with those described in this paper was shipped to the National Research Council of Canada (NRC) on July 28, 1964, via air parcel post. Prior to shipment, it was compared with capacitor number 108. Number 108 was hand- carried to NRC and returned between August 4 and August 17, 1964, and again between December 8 and December 11, 1964. Comparisons of the two capacitors at NRC indicated no relative change in the two capacitances larger than $0.2 \mathrm{ppm}$; and as can be seen from table 1, no change in number 108 occurred during either of the two round trips.

\section{Conclusion}

Much more data is needed to evaluate conclusively the reliability of the 1964 set of fused silica dielectric capacitors. Existing evidence suggests that stabilities in the order of a few parts in $10^{7}$ may be expected, and that the capacitors can probably withstand normal handling during shipment between laboratories.

Some further modifications of the design may result in an improved standard. A study of the mechanism which produces the capacitance hysteresis effect with large temperature changes would be of value, and consideration might be given to improving the support system for the fused silica element.

It is felt that the choice of $10 \mathrm{pF}$ for a fused silica dielectric capacitor results in a design of nearly optimum stability. Other values would be useful as secondary standards and should not be difficult to construct.

\section{References}

[1] M. Kanno, Researches on standard capacitors, researches of the electrotechnical laboratory (Japan), No. 597, April 1961 (in Japanese).

[2] R. D. Cutkosky and L. H. Lee, The construction and behavior of a transportable ten picofarad capacitor, comite consulatif d'electricite, Aupres Du "Comite International Des Poids et Mesures," 10 Session 1963, p. 44.

[3] Standard capacitors and their accuracy in practice, Notes on Applied Science 13, (NPL) 1955.

[4] J. Q. Shields, The voltage dependence of precision air capacitors, to be published.

(Paper 69C3-196) 